\title{
Ocuppational stress, working condition and nutrional status of military police officers
}

\author{
Ângela Maria C. Santana ${ }^{1 a}$; Josiane Keila V. Gomes ${ }^{\mathrm{a}}$; Dione De Marchi ${ }^{\mathrm{a}}$; Yassana M. Girondolia; Lina \\ E. F. P. de Lima Rosado ${ }^{\mathrm{a}}$; Gilberto Paixão Rosado ${ }^{\mathrm{a}}$; Isabel Maria de Andrade ${ }^{\mathrm{b}}$. \\ ${ }^{a}$ Nutrition and Health Department, Federal University of Viçosa - CEP: 36570-000 - Viçosa, MG - Brazil. \\ ${ }^{b}$ Health Division, Federal University of Viçosa - CEP: 36570-000 - Viçosa, MG - Brazil.
}

\begin{abstract}
This study aimed to investigate the relationship between stress, working conditions and the nutritional status of 53 military police officers in a Southeast city of Brazil. In order to evaluate the symptomatology and the stress phase, the Inventory of Stress Symptoms Lipp for Adults - ISSL was utilized. The assessment of the working conditions was performed by means of socio-demographic questionnaire, direct observation and interviews. The nutritional and health conditions were assessed through anthropometric measures, biochemical tests, blood pressure measurements and cardiovascular disease risk calculator. The sample is of the male gender (92.5\%) and aging below 40 years old (73.6\%). From these, $35.8 \%$ showed stress and $68.4 \%$ were in the resistance phase, with $31.6 \%$ almost burned out. Through the calculation of Chi-square we could find positive association between the BMI and tiredness $(\mathrm{P}=0.0188)$, between the BMI and irritation $(\mathrm{P}=0.0005)$ and the $\mathrm{BMI}$ and the appearance of nervous system problems or emotional problems $(\mathrm{P}=0.0304)$, indicating that these statuses or problems could be related to work. We can conclude then, the stress is present among military police officers. No case of critical stress was found, and the stress phases identified are still susceptible to intervention.
\end{abstract}

Keywords: Psychological stress; Working conditions; Police; Nutritional status

\section{Introduction}

Military police is a profession characterized as a high-risk activity, considering that those professional lead with violence, brutality and death in their work routine basis. Currently, it is discussed that police officers are among the professionals who suffer most because of stress, and because they are constantly exposed to danger and aggression and because they intervene in situations with human problems with much conflict and tension [4].

Occupational stress is understood as the unbalance between work demands and workers capacity of response. Stress factors as high demand, low control of the work process, frequent contact with the public, long work hours, the insufficient material resource, the activity itself, in satisfaction with the salary, difficulty of job ascension in addition to exposure to other's suffering, dangerous situations and family problems, are all related to suffering or psychic disturbances [13].

Stress is present in the origin of many physical and psychic diseases already studied, as contributing or triggering factor and among those diseases it can be cited: hypertension, obesity, depression [13].

Data from VIGITEL (2010) - Vigilância de Fatores de Risco e Proteção para Doenças Crônicas por Inquérito Telefônico - showed that in the last few years, obesity present at an increasing frequency, increasing from $11.4 \%$ of the population in 2006 to $15 \%$ in a survey done in 2010 . It is also notorious the percentage of overweight Brazilian, not necessarily obese: $48.1 \%$. In $2006,42.7 \%$ were above the limit, which means an increase by 5.4 percentage points in the last five years [1].

The increasing prevalence of obesity in Brazil and in the world determined a raise of morbimortality in the patients and consequently higher direct and indirect costs. Evaluation of those costs encompasses

${ }^{1}$ Corresponding author: Ângela Maria C. Santana. Nutrition and Health Department, Federal University of Viçosa, Viçosa, MG, Brazil. CEP: 36570-000 - E-mail:santana@ufv.br - Phone Numbers: (31)38991267 or (31)99655173 
aspects directly related to health services and other sectors of the society as well (preventive care, medical consultation, medicine consumption, hospitalization, diagnose exams and surgeries) and those indirectly related to and regarded to impact on life quality and productivity (presenteesim and absenteeism, morbity associated to lost leisure time and mortality). All those factors have economic significant consequences, that is why obesity is an important public health issue with a strong impact on the economy of a country [1].

Obesity is an independent risk factor for cardiovascular disease but it is important to highlight the strong association of obesity with dyslipidemia, hypertension and diabetes. The greatest prevalence of hypertension in obesity is attributable to hyperinsulinemia due to resistance to insulin in obese individuals, mainly in those presenting fat accumulation in the trunk region. Hyperinsulinemia activates sympathetic nervous system and tubular reabsorption of sodium, contributing to increase peripheral vascular resistance and arterial pressure. Obesity associated to dyslipidemia, arterial hypertension, insulin resistance and hyperinsulinemia and/or glucose intolerance in the same individual, characterizes the metabolic syndrome [3].

Concern with the health of military police officer is justified by the narrow relationship between them and work conditions, interfering with development and the individual productivity and in the last case in the services to the society. So far, there are few published national works which evaluated health conditions of military police officers, especially regarding to their nutritional status. The daily work rhythm and responsibility to society may lead those individual to stress situations, which, together with a poor alimentation and physical inactivity may initiate development of metabolic complications and cardiovascular disease.

Therefore, the objective of this study was to investigate the relationship between stress, work conditions and nutritional and health status of military police officers in a city in southeast Brazil.

\section{Material and methods}

This work was a transversal study, carried out with lieutenants, sergeants, corporals and privates in a military police company in a southeastern Brazilian city, from August 2009 to August 2010.
The Military policy company disposed of 85 military police officers, 80 males and 5 females at the study period. The participation of those police officers in the study was conditioned to their interested in participating and also by their consent. Initially, 71 police officers agreed to take part in the study, but because of transfers and desistance during the study, the final sample was composed of 53 police officers.

Sample characterization was done by applying a social-demographic questionnaire.

To evaluate the presence, and symptoms and the stress phase the police officers were in, it was used the Inventory of Stress Symptoms Lipp for Adults ISSL, adapted by Lipp (2000) [7], favorable evaluated by Conselho Federal de Psicologia (Brazilian Federal Psychology Counsel), through edict CPF No1 on September $17^{\text {th }}, 2003$.

ISSL uses a quadriphase model, and each phase reflects stress intensity: alert, resistance, almostexhausted and exhausted. It is composed of 37 physical symptoms and 19 psychological symptons; some of them are repeated and differentiated only in intensity terms. Those symptoms are organized in three pictures. The first picture evaluates the alert phase, it includes 12 physical symptoms and three psychological symptoms. The participant checks the physical or psychological symptoms which was experimented by him or her in the last 24 hours. The second picture is composed of 10 physical and five psychological symptoms. The almost-exhaustion phase is diagnosed based in a greater frequency of symptoms listed in the picture 2 of the inventory. Lastly, the third picture, which evaluates exhaustion phase, presents 12 physical and 11 psychological symptoms, and the participants check the ones it was experimented in the last month [4].

Nutritional evaluation was carried out considering anthropometric evaluation, with measures of weight, height, waist circumference, body composition and body mass index (BMI).

The police officers were weighed on scale with maximum capacity of $150 \mathrm{~kg}$ and $100 \mathrm{~g}$ division (Tanita). The participants were guided to place themselves in the center of the scale, barefooted wearing as less clothes as possible and to stare at a point in front of them to avoid oscillations on weight measurement [6].

Height was measured with a metal tape (Microtoise-Stanley), with a $2.00 \mathrm{~m}$ extension, divided in centimeters and subdivided in millimeters, with a plastic visor and a set-square coupled at one of the tape extremity. Participants were barefooted, in erect position, with their backs leaning a vertical plan (a 
wall without door) looking at the horizon, with jointed heels, making a $45^{\circ}$ angle [6].

Body mass index (BMI) was calculated from weight and height measures, by using the formula BMI $=$ weight $(\mathrm{kg}) /$ height $^{2}\left(\mathrm{~m}^{2}\right)$. BMI was used for nutritional status raking, using the cut-off points for adults preconized by WHO/FAO [14] 2003, that is, low weight (BMI < 18.5); eutrophic (BMI 18.524.99); overweight (BMI 25-29.99) and obesity $(\mathrm{BMI} \geq 30.00)$.

Waist circumference was obtained by considering 2-cm measure above umbilical scar by using a glass fiber tape, in centimeters, with millimeter subdivision, flexible and inelastic. The cut-off points preconized by WHO [15] (1998) to evaluate risk of metabolic complications development according to the risk degree for cardiovascular diseases: risk increased for women $(\mathrm{WC}>80 \mathrm{~cm})$ and for men $(\mathrm{WC}>94 \mathrm{~cm})$, and risk much increased for women $(\mathrm{WC}>88 \mathrm{~cm}$ ) and for men $(\mathrm{WC}>102 \mathrm{~cm}$ ).

Body fat was evaluated by tetrapolar bioimpedance biomethod (Biodynamics analyzer model 310 ). This was carried out with the individual laying on a non-conductive surface, at supine position, with hands and legs abducted at $45^{\circ}$ from the body. Immediately after the electrodes were placed, contact areas were cleaned with alcohol for positioning of electrodes. An electrode issuing was placed close to the metacarpal-phalanx joint on the right hand dorsal surface and the other distal from the transverse arch of the superior surface of the right foot. A detector electrode was placed between distal prominences of the radius and ulna of the right wrist, and the other, between medial and lateral malleolus of the right ankle, according to recommendations of the manufacturer. Values of cut-off points used were the ones proposed by NIH/WHO BMI Guidelines [2].

Evaluations of health conditions were carried out by arterial pressure standardization, biochemical tests, test of fasting glucose, cholesterol and trygliceridemia. It was collected data on family records of disease, and the variables of interest were the presence of mellitus diabetes, arterial hypertension (>140/90 $\mathrm{mmHg}$ ), obesity and dyslipidemia. The three biochemical parameters (glucose, cholesterol and triglycerides) were measured by Accutrend ${ }^{\circledR}$ GCT monitor and Roche test tapes.

Measurements were carried out with participants in fasting. By using a lancing and disposable lancets, two or more small punctures were done on the fingers of one of the hands of the participants, from where three blood drops were taken, one for each tape and the readings were performed by the monitor and the value appeared immediately on the visor. Standardization of arterial pressure was done by using digital pressure meter on the upper left arm (ULA) with the individual sitting after resting for 5 minutes. For the evaluation, it was considered the classification according to the IV Brazilian Guidelines for Blood Pressure.

For data analysis, it was used SPSS Statistics 17.0 and MedCalc Statistical Version 9.4.2.0. Statistical level of significance was considered at $5 \%$.

The study was approved by Ethics Committee in Research Involving Human Beings of Federal University of Viçosa.

\section{Results}

The police officers under study are most of them male $(92.5 \%)$, younger than 40 years old $(73.6 \%)$, married $(60.4 \%)$, with two children $(34.0 \%)$, and high-school graduated (64.2\%). They present average age of 34.39 years old with a standard deviation equal to \pm 7.35 , and average age of 35 years old.

The Military Police company in this study has the following hierarchy organization: Major, Captain, First-lieutenant and Second-lieutenant, corporal and privates.

Concerning hierarchy, it was seen in the sample a predominance of soldiers and corporal (86.7\%) Figure 1.



Figure 1. Distribution of military police officers according to ranking.

Of the analyzed individuals, $35.8 \%$ presented stress and out of those, $13.2 \%$ presented stress in aggravation process because they could be framed in two or more stress phases at the same time, and the one considered for diagnose was the one which presented more percentage of physical symptoms and/or psychological, according to guidelines of use of ISSL tool, of Lipp (2000) [7]. 
Among the ones who presented stress, $68.4 \%$ were in the resistance phase and $31.6 \%$ were in the almostexhaustion phase. Regarding symptom manifestation, there was no predominance of an area, and predominance of physical and psychological symptoms was $47.7 \%$. 5.2\% presented predominance of both symptoms. Among diagnose of the presence of stress, $84.2 \%$ were privates or corporal and $15.8 \%$ were sergeants or lieutenants.

It was also questioned to the sample the presence of tiredness, irritation, nervous or emotional problem and pain in some part of the body related to work performance. Most reported feeling tiredness and irritation, as it can be seen in Table 1, which presents other results related to work conditions. Parts of the body presenting the most cited pains were lower limbs (15.1\%), column (9.4\%), head (5.7\%), column and lower limbs together (5.7\%) and head and column together $(3.8 \%)$.

Table 1

Distribution of the variables related to working conditions of the military police officers

\begin{tabular}{|c|c|c|}
\hline Variables & $\mathbf{n}$ & $\%$ \\
\hline \multicolumn{3}{|l|}{ Weekly work hours } \\
\hline Up to 40 hours & 26 & 49.1 \\
\hline Above 40 hours & 27 & 50.9 \\
\hline \multicolumn{3}{|l|}{ Salary range } \\
\hline 2 to 4 minimum wage & 28 & 52.8 \\
\hline$>4$ to 7 minimum wage & 20 & 37.7 \\
\hline$>7$ a 10 salários & 5 & 9.4 \\
\hline \multicolumn{3}{|l|}{ Work-related tiredness } \\
\hline Yes & 37 & 69.8 \\
\hline No & 16 & 30.2 \\
\hline \multicolumn{3}{|l|}{ Work-related irritation } \\
\hline Yes & 32 & 60.4 \\
\hline No & 21 & 39.6 \\
\hline \multicolumn{3}{|c|}{$\begin{array}{l}\text { Work-related nervous or emo- } \\
\text { tional problem }\end{array}$} \\
\hline Yes & 23 & 43.4 \\
\hline No & 30 & 56.6 \\
\hline \multicolumn{3}{|c|}{ Work-relatated pain emergence } \\
\hline Yes & 27 & 50.9 \\
\hline No & 26 & 49.1 \\
\hline
\end{tabular}

Anthropometric and health profile presented in Table 2 showed that the sample typically has overweight $(64.1 \%)$, present low risk of cardiovascular diseases $(32.1 \%)$ in relation to waist circumference and present over body fat or high fat percentage $(72.0 \%)$.
Table 2

Distribution of variables related to nutritional status or health condition of military police officers

\begin{tabular}{|c|c|c|}
\hline Variables & $\mathbf{n}$ & $\%$ \\
\hline \multicolumn{3}{|l|}{ BMI } \\
\hline Low weight & 1 & 1.9 \\
\hline Eutrophic & 18 & 34.0 \\
\hline Pre-obese & 24 & 45.3 \\
\hline Class I obesity & 6 & 11.3 \\
\hline Class II obesity & 4 & 7.5 \\
\hline \multicolumn{3}{|l|}{ Waist circumference } \\
\hline No risk & 36 & 67.9 \\
\hline Increased risk & 11 & 20.8 \\
\hline Much increased risk & 6 & 11.3 \\
\hline \multicolumn{3}{|l|}{ Fat percentage } \\
\hline Low & 4 & 8.0 \\
\hline Healthy & 10 & 20.0 \\
\hline Excess & 26 & 52.0 \\
\hline High & 10 & 20.0 \\
\hline \multicolumn{3}{|l|}{ Blood pressure } \\
\hline Optimum & 16 & 30.2 \\
\hline Normal & 26 & 43.4 \\
\hline Limitrophe & 5 & 9.4 \\
\hline Hypertension I stage & 3 & 5.7 \\
\hline Hypertension II stage & 2 & 3.8 \\
\hline Hypertension III stage & 1 & 1.9 \\
\hline Isolated systolic & 3 & 5.7 \\
\hline \multicolumn{3}{|l|}{ Fasting glucose } \\
\hline Hypoglycemia & 35 & 87.5 \\
\hline Normal & 5 & 12.5 \\
\hline \multicolumn{3}{|l|}{ Total cholesterol } \\
\hline Normal & 26 & 66.7 \\
\hline High & 13 & 33.3 \\
\hline \multicolumn{3}{|l|}{ Triglycerides } \\
\hline Normal & 32 & 80.0 \\
\hline High & 8 & 20.0 \\
\hline
\end{tabular}

Among stressed police officers, $73.68 \%$ were overweight or obese, a significant result inasmuch as obesity may be related to stress and both factors favor development of metabolic complications. Although some studies related overweight to stress, there was no association among those variables in this study $(\mathrm{p}>0.05)$.

About stress diagnosed individuals, $68.42 \%$ reported that they and/or their family members has blood hypertension. There was no association among stress presence and blood hypertension $(p>0.05)$. Regarding to the blood pressure standardization which was carried out, $31.58 \%$ of the stressed military police officers also presented altered blood pressure, according to classification used by the IV Blood 
Pressure Brazilian Guidelines [8] (2004). But, there was no association among stress and altered blood pressure $(p>0.05)$.

Concerning to family records of diseases, $36.84 \%$ reported obesity cases in the family, $57.89 \%$ reported cardiovascular diseases, $47.37 \%$ reported hypertriglyceridemia and $52.63 \%$ reported cases of hypercholesterolemia, out of those who presented stress.

Stress, overweight, accumulation of abdominal fat, blood pressure, diabetes mellitus, dyslipidemias are risk factors for cardiovascular disease plausible of control.

Prevention and control of obesity and other complications, healthy lifestyle and nutritional education may result into desirable alterations as for example reduction of weight and lipids and glucose blood levels and reduction of blood pressure levels as well. Thus, some strategies and prevention action were proposed to reduce and avoid excessive stress and nutritional guidelines for a healthy lifestyle were also proposed in printed material given to the participants after the study.

\section{Discussion}

It is observed that most people working as police officers are men, and the result of this work for gender variable was not different. According to Souza et al. (2007) [13], even with the evolution of the female participation in the police work force, activities inherent to police work are still considered as male. Still, according to Moraes et al. (2000) [10], female insertion in Minas Gerais Military Police occurred late, from 1980s, and this late insertion might have occurred due to the contrary idea that society has of women working as police officer, that is, the docile and fragile representation of women does not agree with the social imagery of force, power and virility of the police which are traits of the male symbolic universe itself. Those factors collaborate for the small female participation in the police work force.

In a study carried out with military police officers in Natal, Rio Grande do Norte, Costa et al. (2007) [4], observed results very similar to the socialdemographic data, in which the sample was made up of men $(95.5 \%)$, younger than 40 years old $(87.5 \%)$, married (53.8\%), high school graduated $(77.3 \%)$. Moraes et al. (2000) [10] also noted results similar to this work in their study carried out with military police officers in Minas Gerais, regarding to personal data, and the sample was composed mainly of male individuals $(94.5 \%)$, younger than 40 years old $(89.1 \%)$ and married $(60.9 \%)$.

Although less than half of the sample had presented stress and the percentage found in this work is less than the one found in other studies which used ISSL of Lipp (2000) [7] as a tool, the result must be considered because as it is shown in many studies, stress results in many physical, psychological and emotional harms in the individual presenting it.

The stress phases in which the police officers are in are those in which it is possible to deal with tension and to eliminate the symptoms. However, if the analyzed individuals do not have strategies to deal with stressor events, they will be subjected to a debilitation of the organism and to the installation of phases following stress, and they may reach exhaustion phase.

The most serious diseases arises in this phase because of the immune system weakening, with the emergence of diseases as for example blood hypertension, skin problems, depression, anger, anxiety, anguish, apathy, humor changing and emotional hypersensitivity, making intervention of skilled professionals indispensable [4].

The importance of knowing which predominance of symptoms in a person who present stress consists in knowing which the vulnerable area of the person is, if it is physical or psychological, to indicate preventive actions or the most adequate treatment. It should be also considered that each person may present different reactions in the presence of stress.

In a study carried out with military police officers in Natal, Costa et al. (2007) [4] observed that 47.4\% of the police officers presented stress, a percentage greater than the one found in this work. Out of the $47.4 \%$ with stress, $3.4 \%$ were in the alert phase, $39.8 \%$ in the resistance phase, $3.8 \%$ in the almostexhaustion phase and $0.4 \%$ in the exhaustion phase. Psychological symptoms were recorded in $76.0 \%$ of the police officers with stress and physical symptoms were recorded in $24.0 \%$. Those results differ from the ones in this study.

Concerned with hierarchy, Moraes et al. (2000) [10] observed in a study with the military police in Minas Gerais, that the sample was mostly composed of corporal and privates $(57.7 \%)$, followed by subaltern officers (35\%) and superior and intermediary officers $(7.3 \%)$.

It can be said that in this study, military police corporal constitute the hierarchy level who most presented stress, 52.6\%. However, the tests did not show a significant association between hierarchy level and stress $(p>0.05)$. 
In their study with military police officers Costa et al. (2007) [4] did not find significant association between police rank and stress $(\mathrm{p}>0.05)$, but they did find existence of representative stress levels in all hierarchy ranks, particularly among superior and intermediary officers $(55.6 \%)$ and corporal and privates (49.5\%), a result different from this study.

It can be seen that $50.9 \%$ of the police officers had a weekly work hours superior to 40 work hours. Moraes et al. (2000) [10] observed results similar to the ones in this study, in which $46.7 \%$ worked a hours longer than 40 weekly hours. The long work hours, and dissatisfaction with salaries can be stressing factors, contributing to the occurrence of occupational stress.

It was observed a positive association between BMI, tiredness, irritation and emergence of nervous or emotional problems related to work, as it is shown in Table 3. Therefore, it can stated that overweight is associated to physical and/or emotional wear at work.

Table 3

Association between variables tiredness, irritation, nervous or emotional problem and BMI in military police officers

\begin{tabular}{lll}
\hline & \multicolumn{2}{l}{ BMI } \\
\cline { 2 - 3 } & $p$ & $\mathrm{n}$ \\
\hline Tiredness & 0.0188 & 53 \\
Irritation & 0.0005 & 53 \\
Nervous or emotional problem & 0.0304 & 53 \\
\hline $\mathrm{n}=$ frequency; $p=\mathrm{p}$ value & &
\end{tabular}

As it was expected, it was observed a significant positive association between BMI and waist circumference ( $\mathrm{p}=0.0006)$, as it was also observed a positive association between BMI and body fat percentage $(\mathrm{p}=0.0105)$.

Donadussi et al. (2009) [5], found a positive correlation among BMI, abdominal circumference (AC) and body fat percentage. The greater BMI, the greater $\mathrm{AC}(\mathrm{p}<0.001)$ and the greater body fat percentage $(p<0.001)$.those results are similar to the ones in this study.

Overweight is related to a greater overload for the vertebral column during work and emergence of pains on the body. However, it was not observed a positive association between BMI and the presence of any kind of pain $(p>0.05)$ in our study.

Obesity, especially abdominal obesity, is associated to important metabolic alterations, as for example dyslipidemia, glucose intolerance or diabetes and blood pressure [11]. All those metabolic alterations are risk factor for cardiovascular diseases. Thus, risk of cardiovascular disease can be increased for those individuals who presented abdominal fat accumulation and stress.

Overweight individuals, when compared to eutrophic individuals, are at a greater risk of developing mellitus diabetes, dyslipidemia and blood hypertension, which are conditions that favor development of cardiovascular disease [3].

Among police officers who presented stress, $73.68 \%$ were overweight or obese, an expressive result since obesity can be related to stress and both factors favors development of cardiovascular disease. Although some studies relate overweight to stress, it was not found any association between those variables $(\mathrm{p}>0.05)$.

Concerning to family record of some diseases among individuals presenting stress, $36.84 \%$ reported obesity in the family, $57.89 \%$ reported cardiovascular disease and $52.63 \%$ reported hypercholesterolemia cases. Thus, in addition of presenting genetic predisposition for those diseases, those police officers also presented stress, which according to literature also contributes to emergence of those diseases. Those physiologic alterations occurs in the organism in the presence of excessive stress because there is a link of neurological, immune and endocrine systems for realization of regulator functions of the organism and control by internal and external stimuli, as for example stress [12].

\section{Conclusions}

Stress is present in $35.8 \%$ of the analyzed military police officers, especial in corporals $(52.6 \%)$. It was not found a picture of critical stress in the population under study, the stress phases identified can not be intervened before individuals progress to more serious and debilitating phases.

However, it should be considered that besides the presence of stress in $35.85 \%$ of the sample, some of these police officer has in addition other proven risk factors for metabolic alterations as for example abdominal fat accumulation, overweight and genetic predisposition to non-transmissible chronic diseases. It was also observed that approximately half of the police officers in the sample $(50.9 \%)$ has a weekly work hours superior to 40 hours, which can contribute to tiredness, irritation and stress.

Other studies in this field should be carried out in other Brazilian police cooperation to allow a compa- 
rison among the obtained results, which may confirm or enlarge or even refute the findings in this work.

\section{References}

[1] ABESO. Custos da Obesidade no Brasil e no Mundo. Disponível em: <http://www.abeso.org.br>. Acesso em: 14 março 2011.

[2] Body Fat Percentage. Disponível em: $<$ http://www.weightlossresources.co.uk/body_weight/body_fa t/percentage.htm $>$. Acesso em: 01 junho 2010.

[3] Carneiro G, et al. Influência da distribuição da gordura corporal sobre a prevalência de hipertensão arterial e outros fatores de risco cardiovascular em indivíduos obesos. Rev Assoc Med Bras. 2003; 49(3): 306-11.

[4] Costa M, Accioly Jr H, Oliveira J, Maia E. Stress: diagnóstico dos policiais militares em uma cidade brasileira. Rev Panam Salud Publica. 2007; 21(4):217-22, DOI: 10.1590/S102049892007000300004.

[5] Donadussi C, Oliveira AF, Fatel ECS, Dichi JB, Dichi I. Ingestão de lipídios na dieta e indicadores antropométricos de adiposidade em policiais militares. Rev. Nutr. 2009; 22(6):847-55. DOI: 10.1590/S1415-52732009000600006.

[6] Jelliffe DB. Evaluación del estado de nutrición de la comunidad. Genebra, OMS, 1968. (Serie de Monografias, 53).

[7] Lipp, MEN. Manual do Inventário de Sintomas de Stress Para Adultos de Lipp (ISSL). São Paulo: Casa do Psicólogo, 2000.

[8] IV Diretrizes Brasileiras de Hipertensão Arterial. Arq Bras Cardiol. 2004; 82: 7-14
[9] Malagris LEN, Fiorito ACC. Avaliação do nível de stress de técnicos da área de saúde. Estud. Psicol. 2006; 23(4):391-98.

[10] Moraes LF, Marques AL, Pereira LZ. (2000). Diagnóstico de qualidade vida e Stress no trabalho da Polícia Militar do Estado de Minas Gerais [relatório de pesquisa]. Belo Horizonte: Núcleo de Estudos Avançados em Comportamento Organizacional. Centro de Pós-Graduação e Pesquisas em Administração. Universidade Federal de Minas Gerais.

[11]Rezende FAC, et al. Índice de Massa Corporal e Circunferência Abdominal: Associação com Fatores de Risco Cardiovascular. Arq Bras Cardiol. 2006; 87(6):728-34. DOI: 10.1590/S0066-782X2006001900008.

[12] Rossetti, MO, et al. O inventário de sintomas de stress para adultos de lipp(ISSL) em servidores da polícia Federal de São Paulo. Rev. Bras. ter. cogn. 2008; 4(2):108-19. ISSN 18085687.

[13] Souza ER, Franco LG, Meireles CC, Ferreira VT, Santos NC. Sofrimento psíquico entre policiais civis: uma análise sob a ótica de gênero. Cad. Saúde Pública. 2007; 23(1):105-14. DOI: $10.1590 / \mathrm{S} 0102-311 \mathrm{X} 2007000100012$.

[14] WHO/FAO Expert Consultation. Diet, nutrition and the prevention of chronic diseases. 2003. n. 916. World Health and Organization. Geneve, 2003.

[15] World Health Organization. Obesity: preventing and managing the global epidemic. Geneva: WHO; 1998. Report of a WHO Consultation on Obesity. 